CIFRAS DE HOY Rev Chil Salud Pública 2013; Vol 17 (1): 26-27
Extractos de Temas de Coyuntura № 56 Noviembre 2012, Asociación de Clínicas AG (disponible en http:/ /www.clinicasdechile.cl/ Coyuntura_56.pdf, a su vez basado en el Informe Why Not the Best, que analiza los resultados de "Commonwealth Fund National Scorecard on U.S. Health System Performance, 2011", publicado en octubre 2011 [con autorización de los editores de Temas de Coyuntura]).

\section{Sistema de salud de Estados Unidos: ¿Por qué no son los mejores?}

\section{The United States Health System: Why isn't it the best?}

El resumen producido por Temas de Coyuntura no sólo evalúa el resultado del sistema de salud de los Estados Unidos y lo compara con naciones europeas, sino que además lista los criterios de evaluación y explicita los valores seriados en el tiempo.

Constituye un valioso elemento para ponderar el desempeño en materias de interés público, de un sistema de alto costo y basado en mecanismos de precios y seguros privados. La evaluación considera 5 dimensiones, especificadas en una variedad de parámetros: vida saludable, calidad, acceso, eficiencia y equidad. Calidad es la dimensión que considera mayor cantidad de indicadores y ellos pueden ser de utilidad para problemas que también son nuestros.

En la comparación, el sistema de Estados Unidos muestra resultados mediocres. En su propia evaluación promedio de los 42 indicadores, respecto al año 2006, la situación es de una leva baja. Si bien en algunos aspectos ha avanzado

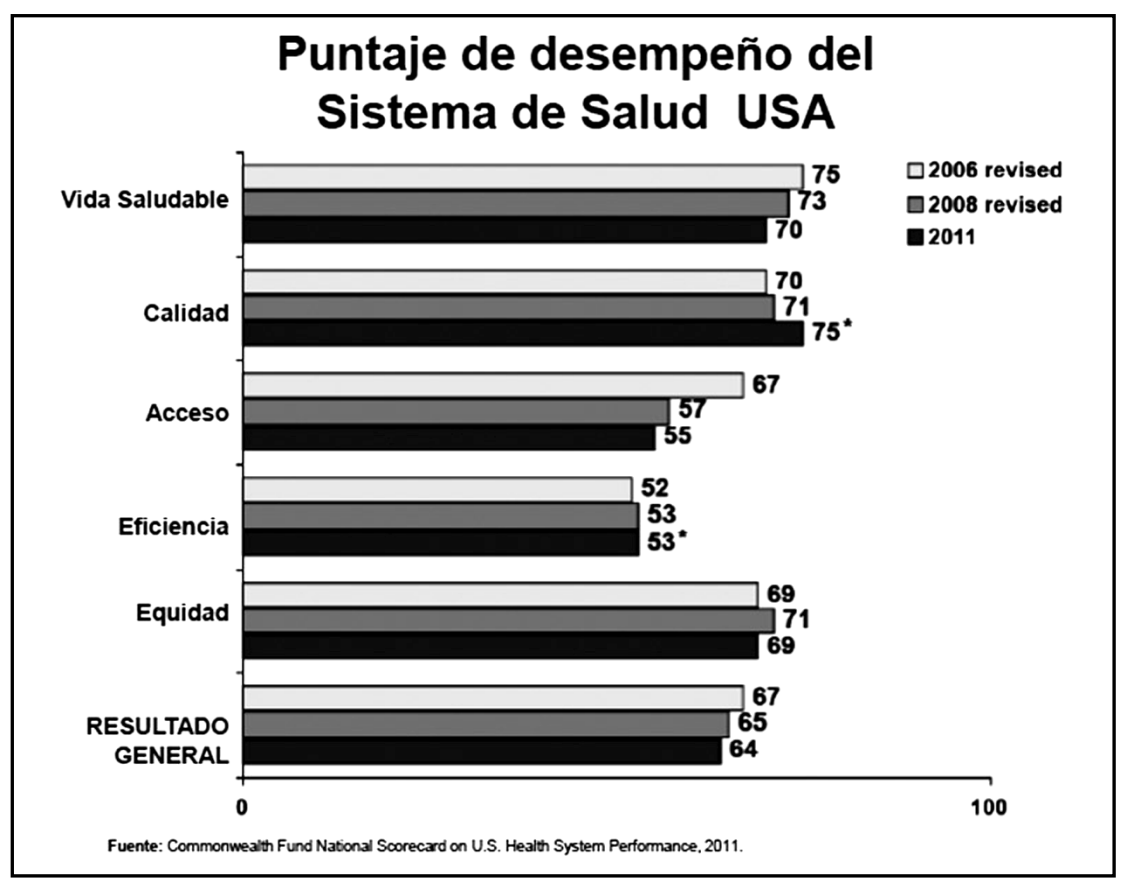


como informatización, cuidados hospitalarios, tabaquismo, ese desempeño ha evolucionado con menos velocidad que los países con los cuales se compara. Como zonas de retroceso destacan acceso, equidad, atención primaria y obesidad infantil.

El reporte que citamos concluye: «De acuerdo al análisis realizado por la Fundación Commonwealth, ellos concluyen que Estados Unidos está perdiendo terreno en el esfuerzo para garantizar el acceso a la atención de la salud eficiente. Aunque hay mejoras prometedoras en los principales indicadores de calidad de la atención, estos siguen siendo desiguales a nivel geográfico, entre establecimientos y entre personas. También estiman que hay amplia evidencia de atención ineficiente e inequitativa. Otros países avanzados los están superando en la tarea de proporcionar acceso oportuno a la atención primaria, la reducción de la mortalidad prematura, y aumentar la esperanza de vida saludable, gastando considerablemente menos en salud y administración.

Un aspecto muy importante de destacar es que la mejora en los indicadores clave de calidad demuestra que el progreso significativo es posible si el país establece metas y objetivos específicos vinculados a las métricas de desempeño y rendición de cuentas por los resultados. Este enfoque es una necesidad urgente para mejorar el rendimiento en todos los ámbitos y entornos de atención. El rendimiento del sistema de salud tendría que mejorar en un $40 \%$ o más para alcanzar a los niveles de referencia a nivel nacional e internacional». 